\title{
Exploration and Rethinking: Children-Voice Studies in China
}

\author{
KAN Wei \\ Beijing Normal University, Beijing, China
}

\begin{abstract}
This paper reviews children-voice studies in mainland China over the past 10 years in the context of the globalisation era. The traditional grand narrative in the field of contemporary education research in China has been challenged by individual recounts and by concernsregarding the situation in the classroom, which is reflected in the children-voice studies conducted by young researchers. The paper begins with background regarding society, culture, and schooling, continues on to describe related studies in this field, and ends with a rethinking of current research. The conclusion is that the studies were hampered both by an inherited culture of inertia and cynicism towards students' voices and by a dysfunction in research methodology.
\end{abstract}

Keywords: children-voice, grand narrative, methodology

\section{Introduction}

Researches on pupils' experiences are not new in western countries (Dewey, 1913/1975, 1916/2005), but it seems to be ignored by most of Chinese researchers. Despite China's emergence as one of the top countiries of PISA (Programme of International Students Assessment) since 2009, relatively little is known in other countries about Chinese children's voices on their experiences of schooling and life. People might have gained some insights either through naratives of adults, or from the art works which reflect their perspectives. Otherwise, the prevailing impression is that students in China are well-behaviored, learn by rote, and that much in the schools is about memorising and cramming for examinations.

This study seeks to provide a more nuanced and accurate picture of chidlren's voices in China, according to the chronological representatives literatures. As China encompasses such a diverse spectrum of economies, societies and cultures, studies on understanding children voices in various regions are still thin. The children voices are not simple expression on their learning issues of knowledge, but have their own source, nature, structure and content. In the context of Chinese schooling and society, it is often that childrens voices had been ignored. This study attempts to illustrate the historical process of losing voices of children since accient China to the beginning of new republic, according to the poems and essays in Chinese history, individual experiences and the ideological function of restriction on children's voices in political system. Meanwhile, this study displays the social factors that impact on expressions of children voices.

\section{Background: Silence of Children's Voices in Traditional Chinese Education}

Chinese society expects a great deal from its children. Nonetheless, there are relatively few academic studies

KAN Wei, Doctor of Philosophy, Associate Professor, Faculty of Education, Beijing Normal University. 
of the children voice.The good news is that the situation is changing in line with an increasing academic focus on students' rights, values, and behaviours (GU, 2003). This paper seeks to provide an account of key foci in the study of childhood voices, while also extending the reach of the works cited to certain writings about "youth". Childhood is a difficult category to pin down, as cultural and social norms can mean that a 16-year-old is a child in one place, but a working adult somewhere else. Here, we keep to the United Nations Convention of the Rights of a Child (United Nations, 2009), of which China is a signatory, and mark infancy up to age two, and childhood up to 17 years of age. However, we have still included references that are concerned with "youth" who are over 17 years old, when those discussions are also pertinent to an overall study of generational change.

China has typically been known as a country with a long history of educating children (GU, 2013). However, children's voices have disappeared from public discourse over the past 1,000 years. As Cotterel points out, ancient Chinese children were deprived of education. Most of them worked on their parents' farms, picking weeds and planting seeds. Only boys of rich families enjoyed the right to go to school (Cotterel, 2000). Similarly, Benn examines the data during the seventh century to the 14th century of the Tang and Song Dynasties (Benn, 2004), emphasising that girls belonging to the higher strata of society were not allowed to go to school. In contrast, to achieve political power, boys had to work diligently in school, as doing well in state examinations was the only way to obtain it (Miyazaki, 1981).

Discrimination between boys and girls existed across all of ancient Chinese society. For ancient Chinese people, sons were more important than daughters and since the Han Dynasty (B.C. 202-A.D. 220). It has been said that "obtaining jade is as joyous as having a son", but having a girl is like "getting a slate". Female infanticide also prevailed in ancient China. Children were expected to know their limits in the family and be obedient, rather than speak their opinions and thoughts to the family (Gernet, 1963). Particularly, Chinese Confucian education with its revered institutions privileged texts of elders, ancestors, and worthies of antiquity, promoting the study of classical texts and moral exemplars of ages past so as to gradually shape the child according to canonical moulds (Ebrey, 1993). Some Chinese researchers argue that ancient Chinese practices did not produce a philosophy of respect for children or their ideas (YIN, 2009). In Confucian philosophy, three cardinal guides (ruler guides subject, father guides son, and husband guides wife) and Five Constant Virtues (benevolence, righteousness, propriety, knowledge, and sincerity) show the basic principles of filial piety as the backbone of traditional ethics. They emphasize the hierarchical relationships between parents and children, to deny that love exists between father and son. As a result, core values were dominated by the three cardinal guides, which emphasized fathers guide their sons in the traditional family (XIA, 2001).

JI's study analyses preformation theory, which holds that ancient philosophy deeply impacted the understanding of children for centuries to come. His study also focuses on the image of children in ancient Chinese literature. He argues that in the Song Dynasty (11th century-14th century), children were typically described as the spokes people of mysterious forces. He also points out that boys and girls were treated differently in ancient China, with girls being deprived of education even if they belonged to the higher strata of society. At the same time, the civil service-exam system—which had a positive role in accelerating reasonable social mobility and constructing social equality—broke the old system of social stratification and played a vital function in education, with even poor children having a chance of obtaining political power as they could study in private academies (JI, 1992). 
It should be noted that even though children had no voice in ancient China, some vividly recorded their feelings and understanding of the world in poems, expressing deep feelings with childlike innocence. These poems had several forms such as song proverbs in children's folk rhymes, ditties, odes, or songs. Sometimes they became incorporated into the wordsused in games. LUO Bin-wang, a typical seven-year-old wrote the masterpiece Ode to the Geese in the middle of the seventh century (Dang Dynasty).

\section{Ode to the Geese}

Geese, O geese!

Your necks curving sing to sky in glees;

Your white plumes float on water green,

Red feet paddle streams clear and clean. ${ }^{1}$

Aside from LUO’s descriptions of geese, there are Ode to the Rabbit (written by a seven-year-old poet, Tang Dynasty), White Lotus (written by a five-year-old poet, Song Dynasty), and Pines (written by a seven-year-old poet, Song Dynasty). Written by young children, these poems reflect the harmonious state of childhood life. Another category of poems in ancient China was those created by adults describing the life of children. Examples of these include A Little Girl's Crying in Front of the Tomb (written by MEI Yao-chen, Song Dynasty), Grieving over a Child's Death (written by XU You-ren, Yuan Dynasty), and Whose Family is This Seven-Year-Old Child (written by Yaoxie, Qing Dynasty). Even though children did not write these poems, they were written from the child's perspective and could still strike a responsive chord in the hearts of their contemporary readers.

Apart from the poems created by children themselves and those created for children by adults, nursery rhymes that bring children laughter and joy, help them understand the good and the evil in the world, and tell them how to behave themselves, also played a very important role in giving voice to children in ancient China. Nursery rhymes spread widely in ancient China because of their rich content and vivid representation, and greatly influenced the intellectual development and ideological education of Chinese children. In the Ming Dynasty, LU Kun (1536-1618) edited the first book of Chinese children's folk rhymes. It demonstrated the unique charm of nursery rhymes with a fresh style, plain and clear rhythm, and strong rural appeal.

\section{First Stage: Understanding Children's Voices in Modern Times: Beginning of the 19th Century Through the 1940s}

As LU argues, rethinking attitudes towards the opinions of young people in modern China can be traced back to the beginning of the 19th century. With the expansion of Western colonialism in the 1840s, ideas regarding modern western education began to influence the Chinese upper classes. The western trend of thought for respecting the rights of children was a breakthrough for understanding children through comprehensive study and helped to breach the doctrine and standard outlook for children that had dominated for centuries in China (LU, 2007). Chinese government officers were sent abroad, young people of affluent families studied abroad to learn Western techniques and skills, and the word "children" as a specific term was introduced, first appearing in an official document in 1902. This indicated that the perception of children had changed, with their importance

${ }^{1}$ The poem is made by LUO Bin-wang (619-684). 
as individuals being greatly raised, and that Chinese society was entering an era of emancipation and discovery of children (SHU, 1960; HE, 1990).

The first document that recorded the lives of Western children from the perspectives of Chinese officers was written by three 18-year-old mandarin boys, who were educated in the first modern school setup by the Qing government. Their travel notes focused on France, the UK, the Netherlands, Denmark, Russia, Germany, and Belgium, and recorded their interest upon witnessing the birth of Western children, educational environment, and public primary and secondary schools (ZHONG, 1985). In the following years, a systematic investigation of Japanese primary and secondary school education was undertaken because they too were influenced by Western culturein China started in 1898.

Since the 1920s, scholars who return from Japan and the US have established a trend of rethinking attitudes towards the lives of children. These scholars are the first who revealed the life and voices of Chinese children at the beginning of the 20th century in China.

Professor TAO Xing-zhi was a 20th`century Chinese educator and reformer who proposed optimising children's developmental environment and caring for their needs (TAO, 1933). Other famous scholars, including the Chinese philosopher, essayist, and diplomat HU Shih and the essayist and translator ZHOU Zuo-ren, showed that health care for Chinese children was stunningly poor and that children were confronted with many challenges that resulted from a lack of scientifically informed care and development (Chou, 1984; Grieder, 1970). These scholars urgently insisted that Chinese people must persist with scientific development to promote harmonious development between education for girls and realize educational equality between boys and girls. TAO and other scholars strongly criticized the popular culture that made a distinction between the sexes and which held to a deliberate educational model of gender inequality.

The voices of children began to be explored by adults, and the appeals for emancipation, particularly for girls, created an interesting perspective on children's voices. Dissatisfaction expressed with gender inequality such as being deprived the right to equal education and having feet forcibly bound clearly reflected the real lives and voices of young girls (XIONG, 2006). They also first proposed that respecting children means respecting the nature of children through their play and games (CHEN, 1934). This raised the status of children to a focus on the "children's own life" and "own world and society" (SUN, 1938).

To understand the voices of students, Magazine of Students-a magazine that was less than 50-pages-long - was published from 1914 to 1918 by Commercial Press in Shanghai. This magazine was precious and unique because many of the essays were created by students themselves.These essays were written by children aged 12-16 years (secondary school students) and were the direct expression of inner feelings and ideas of Chinese students at the beginning of the 20th century (LIU, 1986). Secondary school students were the first group that was formed after abolishing the imperial examination in 1905, which had been carried out for more than a thousand years. They represented a new rising class who had strong responsibilities and identities linked to saving a country that had suffered from wars among warlords and imperialistic aggressors. The voices at the beginning of the last century indicated that those enlightened young people carried indeed the burden of saving the country. The expressions in their essays were full of crisis consciousness and the hope of national salvation. Thus, a cultural change in China around this time towards respecting and promoting science came about not only from the impact of western culture, but was also an inevitable outcome of "national salvation": 
Students realized that in order to save China from national demise, reform was essential and the feudal monarchy and religious authority needed to be removed (FANG, 2008).

Similar sentiments from young people occurred in the 1930s and 1940s, which was a time taken up with the struggle to defeat internal fascist aggressors. In particular, songs written by young students were rich in national styles, the clear-cut atmosphere of the times, and the unique characteristics of self-expression, and therefore it gave confidence to the youth (LI \& QIAN, 2009).

\section{Second Stage: Politics Shaped Students' Voices Under the Red Political Power From the 1950s to 1970s}

Liu argues that the revolutionary victory only ushered in a new time of turmoil. Over the past 50 years, no-one in mainland China has experienced the difficulties that existed at that time. For youth who have grown up since the founding of the People's Republic of China in 1949, the new national situations implied to carry the notion of a termination of the revolutionary era. However, they do not usually realize or reflect upon what the mission of social reconstruction was for those who lived during those times (LIU, 1986).

FANG and his research team published a series of works for the Chinese Children's Culture Research Report since 2011 (FANG, 2011), in which analyse the annual themes of children studies in China, for instance, the report discussed the premodern history of children and childhood, modern histories of childhood and youth, music and literature, television and film, media use with Chinese children. It also reveals that listening to stories and experiences of youths is at the heart of understanding contemporary Chinese society and culture. Generations of children since the mid-20th century have been given the burden of achieving a revolution. After the founding of the People's Republic of China in 1949, children were shaped at the forefront of internal struggles during the Cultural Revolution from 1966 to 1976. In his memoirs, ZHOU gave a detailed account of what happened to the generations of youth that developed in that era, particularly, focuses on China's turbulent political history has created more than the usual gaps among youth when they were in the life course and the Cultural Revolution hit has had a major effect on their subsequent trajectory (ZHOU, 2006).

Children voices display the deepest emotion of young love for their motherland, for their people, for their hometown, and for the Communist Party and its revered leader since 1920s: Chairman MAO Ze-dong. They also reflect how their opinions changed as Marxist scholars. Although students had been involved in political movements, the "cultural revolution" was brought about not by the youth but by political leaders. In his book, Reason and Insaneness, WANG analyzed the voices in turmoil, and focused on the poems created by the Red Guards during the Cultural Revolution (WANG, 1993). In their conversations with the younger generation of the Cultural Revolution, CAI, FEI, and WANG asserted that the primary school students hadlost their reason, and thus offersa psychoanalytic understanding of the young students' fanaticism (CAI, FEI, \& WANG, 2002). The distinguished novelist WANG An-yi describes examples of destiny and absurdity, which reveal what confronted the young generation. Under her pen, students who had been brainwashed by the Ultra-Leftist government destroyed their naïve childhood and transformed their humanistic ideals to humanistic evil (WANG, 1981). Meanwhile, people who were children at the time now recount that some investigations that were carried out ostensibly to uncover subversive adult activity was actually used to harass and undermine those with views that differed from the government. Self expression and language became the tools of political persecution. Children 
could understand from this atmosphere and its social dynamics the complexities of politics even if they were not living amidst totalitarian communists.

As He points out, the lives of Chinese children differed from their Western counterparts who experienced a sexual liberation during this same period. Although there are few documents or works that include the thoughts and voices of children who lived during those chaotic years, most adolescent boys and girls had to deeply hide their feelings and desires regarding sexuality because all language, pictures, and other media regarding sex were seen as sinful by the schooling andstate machinery (HE, 2013).

In the aftermath, children were assigned the task of taking Chinese science and technology to the pinnacle of modernity. REN's photographs tell the story of how students lived and learned at a high school in the 1980s (REN, 2011).

\section{Third Stage: Diverse Voices in the Social Transition Period: A Generation That Differed From the Previous One}

The year 1978 witnessed a historical transition in the realm of ideology and culture in China after a long process of twists and turns. Beginning in the 1980s, Chinese officials and media began to talk about the existence of a youth problem (Hooper, 1985), while Chinese youth themselves were regarded as experiencing an “ideological crisis" (Kwong, 1994). Subsequently, students, especially those youths in colleges and universities, were depicted as "utilitarian and individualistic, kind of self-centered and wounded individuals without thought for the future, mankind, or the motherland; distant from the Communist Party” (LIU, 1984; XU, 2002; XU, 2004). The sociologist, Professor QIAN Min-hui published his book titled Students: To be honest (QIAN, 1998). In the

book, Chinese students themselves scrutinize the exam-oriented education system, which places too much emphasis on rote memorisation rather than on the critical application of concepts. Emerging from such accounts are vivid pictures of young Chinese as viciously overworked and under-rested, and even psychologically damaged, by the pressures placed on them by parents, family, teachers, and Chinese society as a whole (Mullins, 2005; Davey, Lian, \& Higgins, 2007).

Comparative study on the voices of students at universities and colleges reveals the dramatic changes in the goals of the younger generations. Fairbrother's (2011) study shows Marxist-Leninism became the guiding ideology after 1949. Yet, from the early 1980s, in the face of a legitimacy crisis, the leadership shifted toward patriotism as a unifying and justificatory ideology, while still professing ultimate objectives in line with Marxist principles. Fairbrother's book is a comparative study of the political attitudes of patriotism and nationalism held by the university students in Hong Kong and mainland China in the 1990s, with a focus on the factors that led individual students to resist. The researcher demonstrates how the students from these two places, to different degrees, were distrustful of the agents of political socialisation. They wanted to know more about the nation, and were receptive to alternative ways of thinking about the country. Further, by comparing three multiple regression models, the author also shows the relative strengths of the effects that socialisation and critical thinking had on national attitudes (Fairbrother, 2011).

Meanwhile, according to some studies, attitudes of younger generations towards sexuality in China have changed since the economic reforms of the 1980s (e.g., Zhang \& Beck, 1999). Premarital sexual intercourse occurs more frequently among young people, and people in China are now more tolerant toward extramarital 
sexual behaviour. Compared with their parents' generation, who were constrained by culture, ideology, and societal context, youth in the age of information and globalisation can easily access sexual media such as pornographic photographs or videos. As a result, the traditional sexual/moral attitudes of Chinese people have been changed by the influence of modern or western values on Chinese youth, in particular secondary school students.

The history of considering the potential of student involvement as a lever in educational change can be traced back to the end of the 1990s. HUANG (2009) proposed that an individual's voice cannot be acknowledged without identifying human/childrens' rights. In terms of the legitimacy, of their interests, however, children cannot always express their own interests as they cannot recognize their rights by themselves (HUANG, 2009, p. 75). Based on this understanding of legitimacy, some studies regarding young voices consider how those of young children differ from those of students and learners in the context of Chinese schooling (HE, 2013). Re-conceptualising the roles of young people in society has powerful implications for schools. There were more substantive theoretical explanations that promote listening to children voices in the classroom. LIU offers detailed explorations of principles and rationales that focus on the thoughts of students on curriculum change during the first ten years (LI, 2001). Mitra's (2008) research, based on hundreds of interviews and observations at one American urban high school, provides an empirical analysis of voices from older students in addressing efforts to effect school change. It indicates that creating a space in which all group members-youth and adults—could develop a common vision and share responsibility for decisionsas she points out, the theme of children voices in education emerged more prominently in research and practice at the beginning of the 21st century. This is also true for Chinese education.

Most people believe that by the 1990s the one-child per family policy resulted in only-children dominating the student body, in contrast to the earlier baby-boomer generation. Studies on Chinese children voice/s since the 1990s show the unique characteristics of the 1980s generation, especially with regards to awakened individualism and self-awareness (Davin, 1991). Particularly, those millennial youth have been described as having a stronger sense of independence that prioritizes self-interest over other people's interests (Moore, 2005; WANG, 2006). As Cockain mentioned, single children in China were spoiled as little emperors or grandparents as they were growing up in the 4-2-1 family-member structure with anxiously over indulgent parents and parents-in-law are involved in child upbringing in urban China (Cockain, 2011).

Living in the globalized market economy, the recent information explosion has greatly affected Chinese students (Goldman Sachs Foundation and Asia Society, 2003). Some studies have focused on Chinese students' multicultural understanding of beliefs and values in this increasingly diverse and globalized context (ZHAO, LIN, \& Hoge, 2007). One qualitative study explored 105 high school students (sophomores to seniors, ages 15-19) from three city public schools. The interesting finding reveals that the positive aspects of China that these young students held included its long history, rich culture, rapid economic development, and its achieved reforms. Meanwhile, their negative images of China included social problems, pollution, a lack of environmental protection, political corruption, and the exam-oriented education system (ZHAO, ZHOU, \& HUANG, 2008). The study reflects that news media plays vital roles in how Chinese students obtain their knowledge about China.

China's myriad problems with children begin to become clearer as the political environment changes and restrictions on religious policies loosen. For instance, many Chinese Christians are turning their attention to the 
local ministry in southern China that is reaching out to care for some of China's "left-behind children", children who are left behind in villages and small towns when their parents go to the cities to work. These "left-behind" children have already become a major social problem for local governments. MA interviewed 23 students whose age ranged from 5 to 12 years. Their narratives reflected the current dilemma of rural education: The younger generations who stay in their villages without accompanying their parents do not receive the same quality of education as wealthier city students, and what is worse, lack of school-based psychological support and concern. The result is anti-social behaviours and resentment of the rich (MA, 2001).

In recent years, a range of films and reports have been concerned both directly and indirectly with student learning in China and the socialisation process in schools. Chinese School, produced by BBC4 takes as its subject one small town in rural Anhui, and focuses on the lives of a group of children and their families during the course of a single academic year in 2008. This was a rare chance for students to express their frank opinions in front of the British journalists' cameras. Through the individual pupil's stories of hardship, joy, and success, an extraordinary portrait emerges. Chinese School is not just a documentary film of a group of children, but a side of the Chinese students' voices seldom seen. In the same year, the US Public Broadcasting Service (PBS) followed five Chinese students through their final high-pressure year at an elite high school in Sichuan Province. China Prep reflects those pupils who study seven days a week and their lives are regimented almost every minute of the day as they prepare for the end-of-year exam that can determine their fate. For many students from poor or rural backgrounds, a strong performance on the test is the only way to climb the social ladder and excel without connections. Competition is fierce and the majority of high school seniors will be relegated to vocational schools. Above two documentary films are regarded as the typical case studies on Chinese students' voices as there is lack of other resources on understanding their lives in the field of academic community.

Since the 21st century, the call for children voices to be heard has also impacted some Chinese researchers (LI, 2001; YANG, 2000). Focusing on China, education research has extended to such topics as the power of schooling and the relationships between teachers and students (e.g., MA, 2003). As KAN (2009a) comments, there is increasing interest in the right of students to voice their views and opinions in the context of a more open society in mainland China, especially regarding teaching and learning in the classroom. He points out that over the past decades, children voices and experiences in primary and secondary schools have been neglected, and this has been recognized by researchers and the public since the beginning of the 21st century. Echoing studies on children voice in the West, some Chinese researchers have begun to rethink their attitudes towards student perspectives, albeit in a limited way. This study also advocates that in particular, the new curriculum should use inquiry-based learning that is linked with the students' own experiences. Other studies from East China Normal University lend further weight to the need for placing greater emphasis on the views of students and teachers. For example, in her case study of classroom experience, DENG (2000) places a strong focus on individual perspectives on educational events and in teacher pedagogy. TANG (2002) also deliberately focuses on the importance of accounting for student perspectives. A study in Nanning, Guangxi Province investigated primary school life in 2000 through the stories of students. The aim of this qualitative study was to illuminate students' perspectives on the education reforms to add new content to the curriculum which then became embedded in the values and behaviours of the students. Through this, TANG sought to answer the question "why does some reform have limited impact in the classroom?” (TANG, 2002). A central factor that this study reveals as crucial to 
the success of reform initiatives is the need to attempt an alignment between the values inherent in the reform and those of the individuals charged with implementing the reform within the schools. Analysis shows that successful implementation did take place in one primary school, but only where members of staff were aware of the need for such an alignment of values and therefore cooperated and supported the initiative.

In recent years, some studies of student needs have emerged in China (e.g., LI, 1999). These reports argue that students come to the classroom with a pre-existing view of what "appropriate" teaching and learning should be, something that has also been shown by researchers in China (e.g., HUANG, 2009). Students tend to evaluate new teaching methods in light of their preconceptions and expectancies, which is part of their classroom requirements. Dissonance or inconsistency is likely to occur if the introduced pedagogic innovations are inconsistent with previously held beliefs (LI, 2001).

The imperative to take account of students' perspectives in the implementation of complex, systemic educational change has also been highlighted in recent research in Taiwan (e.g., CAI, 2003). The qualitative case study examined collaborative education policies in local primary schools using data collected between 2000 and 2002. A mixture of direct observation, documentary evidence, and interviews with participants is used, and the study describes and analyses the responses of teachers and students to changes in educational policy. The aim was to examine whether and in what ways the needs of students should be considered during periods of policy implementation. One of the main conclusions was that student needs are largely ignored during phases of reform. Consequently, the researchers suggest that it is not enough for school administrators simply to have awareness that students have views as they attempt reform initiatives. They need to consult them directly.

However, most studies in education research, as WU (2000) notes, have not yet focused on students and their points of view on learning. For example, the authors of an official document on inquiry-based learning in China stress that the constructivism teaching method is designed for "pupils' development of their intelligence, ability in communication and learningin classroom or at home"; therefore, inquiry-based learning should be implemented and accepted by all students (HUANG, 2009). It is instructive, controversial, and rather disheartening to read their findings regarding the implementation of inquiry-based learning in some classrooms, in which most of the feedback, comments, and suggestions come from administrators and teachers, rather than students themselves.

Although some academic articles suggest the new curriculum reform and extra-curricular activities should be implemented at the classroom level, the comments and views of students are ignored by administrators, educational researchers, and policy-makers alike. They appear to give no consideration, as Fielding (2001) emphasizes, to "why pupils should speak, what use will be made of the speech after it is heard".

Essentially, underlying these questions for Chinese educational researchers is a challenge to the dualistic acceptance of "teacher" and "student" and to the assumption that "educators stand above their pupils and guide them in their struggle for their 'voice”' (HAO, 2005; LI, 2001; WU, 2000; ZHANG, 2014). Furthermore, WU points out that many researchers claim that students' “chaotic” perspectives (WU, 2000, p. 154) and learning environments undermine the authenticity of their voices in what is idealized as linear curriculum implementation. Thus Wu, echoing Brooker and MacDonald (1999), advises educators and teachers to "discard monarchical conceptions of power and shift [their] focus to notions of power as productive and present in all contexts, regulating all discourses and social interactions in the classroom” (WU, 2000, p. 155). He later (2003) claims that 
schools should reduce their reliance on traditional teacher-student relationships and rethink their conceptions of teacher authority. But another researcher doubts whether we can truly hear students' ideas. LI (2001) notes that although some Western researchers have called for students to find and articulate their voices, the complex Chinese classroom context is beyond their imagination, because "all voices within the classroom are not and cannot carry equal legitimacy and power in dialogue [in] specific Chinese school settings” (LI, 2001, p. 74).

Running through the research literature cited above from liberal, critical, feminist, and poststructuralist views, the issue of children voice has been a concern in education. However, studies of children voice, particularly empirical research, are noticeably sparse in Chinese educational literature. Questions not yet addressed include the means by which researchers might use the breadth of children voices, and the proposed outcomes of seeking children voices. Particularly, little empirical data exist regarding children voices within curriculum implementation in China. Therefore, it has significance for Chinese educational reform that such study places emphasis on the role of student experience and response during curriculum reform and the implementation of a new teaching strategy.

\section{Epilogue: Challenges for Studies on Children Voice in China}

When we queried the literature over recent years in the educational community of mainland China, we found evidence for approaches that genuinely involve children voices in influencing educational change. However, SUN (as cited in ZHONG, 2005) claims that the mere act of listening to students' voices often appears to be an end in itself, and KAN (2009b) stresses that the effect of speaking for students is actually often distorted by the researchers themselves. Confronted with these doubts, we have to admit that some studies that place emphasis on accessing the children voice can be tokenistic. This is an area for debate and transformation in Chinese educational research. Hopefully with a view to reform on the ground!

\section{Conclusion}

This paper reviews children-voice literatures in mainland China over the past 10 years in the context of the globalisation era. It shows children are not just a passive mass of bodies without capacity for autonomy or critical thinking. The traditional grand narrative of Chinese literature has been challenged by individual recounts and by concernsregarding the situation in children's life and schooling since 1990s.

This study begins with background regarding history, culture, and schooling, continues on to describe related literature which concerns on children's voices, and ends with a rethinking of children's development in current Chinese society, which embodies the tremendous gaps between urban-rural, disparities between the Eastern and the Western China. The conclusion is that the understandings on Chinese children's voices had not been given adequate priority as it was hampered both by an inherited culture of inertia and cynicism towards children' voices.

\section{References}

Brooker, R., \& MacDonald, D. (1999). Did we hear you?: Issues of pupil voice in a curriculum innovation. Journal of Curriculum Studies, 31(1), 83-97.

CAI, X., FEI, Z. Z., \& WANG, Y. (2002). The Cultural Revolution and narrative: A dialogue about researches on the Cultural Revolution. Review of Contemporary Writers, 9(4), 44-49. 
CAI, M. L. (2003). Stories in classroom context: Qualitative research on schooling. Educational Journal of Taiwan Normal University (in Chinese), 17, 247-259.

CHEN, H. Q. (1934). Child-psychology and approaches of education for child. In J. LV and H. ZHOU (Eds.) (1994), Selected works of Chen Heqin. Beijing: People Education Press.

Cockain, A. (2011). Student's ambivalence toward their experiences in secondary education: Views from a group of young Chinese studying on an international foundation program in Beijing. The China Journal, (January), 101-118.

Chou, M. C. (1984). Hu Shih and intellectual choice in modern China. Ann Arbor: University of Michigan Press.

Cotterel, A. (2000). Eyewitness: Ancient China. NY: DK Children Press.

Davey,G., Lian, D. C., \& Higgins, L. (2007). The university entrance examination system in China. Journal of Further and Higher Education, 31(4), 385-396.

Dewey, J. (1975). Interest and effort in education. Carbondale, IL: Southern Illinois University Press. (Original work published 1913).

Dewey, J. (2004). Democracy and education: 30th anniversary edition. New York: Continuum. (Original work published 1916)

Davin, D. (1991). The early childhood education of the only-child generation in urban China. In E. Irving (Ed.), Chinese education: Problems, policies and prospects. New York: Garland Publishing.

Deng, W. (2000). Case study on pupils' experience in classroom: Qiaozhen primary school. Educational Journal of Sichuan University (in Chinese), 6(2), 157-164.

Ebrey, B. P. (1993). The inner quarters: Marriage and the lives of Chinese women in the Sung period. California: University of California Press.

Fairbrother, G. (2011). Toward critical patriotism: Student resistance to political education in Hong Kong and China (Hong Kong culture and society). Hongkong: Hong Kong University Press.

FANG, W. P. (2011). Annual report of cultural development of Chinese children. Hangzhou: Zhejiang Publishing House of Literature \& Art.

FANG, W. P. (2008) Students' appeal: Cultural phenomenon and historical understanding in a changing era: Case study on early Magazine of Students (1914-1918). Hangzhou: Zhejiang Publishing House of Literature \& Art.

Fielding, M. (2001). Pupils as radical agents of change. Journal of Educational Change, 2(2), 123-141.

Gernet, J. (1963). Daily life in China on the eve of the Mongol invasion, 1250-1276. California: Stanford University Press.

Grieder, J. B. (1970). Hu Shih and the Chinese renaissance: Liberalism in the Chinese revolution, 1917-1937. Harvard: Harvard University Press.

Goldman Sachs Foundation and Asia Society. (2003). 2003 prizes for excellence in international education. Retrieved from http://www.internationaled.org/prizes/2003.htm

GU, M. Y. (2003). Basic assignment of primary and middle school educational reform. Education for People (RinminJiaoyu), 17(3), 14-19.

GU, M. Y. (Ed.). (2013). Encyclopedia on education. Beijing: Encyclopedia Press.

HAO, J. R. (2005). Learning to listening pupils’ voices. Education in Shanxi, (9), 17-19.

HE, S. L. (2013). Inquiry on disappearance of pupils' voices. Journal of Educational Research, 14(4), 47-51.

HE, X. X. (Ed.). (1990). Brief history of pre-education in modern China. Beijing: Beijing Normal University Press.

Hooper, B. (1985). Youth in China. Harmondsworth: Penguin.

HUANG, W. (2009). The right of voice from teachers and pupils, based on the classroom observation. Educational Research and Experiment, 12(6), 74-79.

JI, Y. (1992). Understanding on children in ancient China. Journal of Children Study, 12(4), 45-48.

KAN, W. (2009a). Survey about pupils' perspectives of history class in three key secondary schools. Beijing Education, (2), 56-59.

KAN, W. (2009b). Whose voices? Who are listening. Journal of Educational Research (in Chinese), 35(2), 9-15.

Kwong, J. (1994). Ideological crisis among China's youths: Values and official ideology. The British Journal of Sociology, 45(2), 247-258.

LI, C. (2001). Do we understand pupils’ own world? Teachers and Education, 4(1), 69-74.

LI, J. X., \& QIAN, B. (2009). Students’ voices in the songs of struggling in the anti-Japanese war. Social Science in Hubei, 11(5), 113-116.

LI, Z. X. (1999). Step into students' mind-Notes of democratic education in school. Chengdu: Sichuan Children Education Press. LIU, A. P. (1984 September). Opinions of youth in the People’s Republic of China. Asian Survey, 24(9), 976-977.

LIU, X. F. (1986). Poetic philosophy. Jinan: Shandong Publishing House of Literature \& Art. 
LU, K. J. (2007). Emancipation and discover: Study on outlook of children in modern China (unprinted Ph.D. thesis (in Chinese), n, Education Department, Central China Normal University, Wuha).

MA, W. N. (2001). Survival from the outside perspectives of schooling: Encounter on campus. Beijing: Beijing Normal University Press.

MA,W. N. (2003). Understanding the vulnerable groups in classroom. Educational Theory and Practice (in Chinese), 27(12), $11-14$.

Miyazaki, I. (1981). China’s Examination Hell: the civil service examinations of imperial China. (C. Schirokauer, Trans.). Washington: Yale University Press.

Mitra, D. L. (2008). Children voice in school reform. Albany, NY: Suny Press.

Moore, L. R. (2005). Generation Ku: individualism and China’s millennial youth. Ethnology, 44(4), 357-76.

Mullins, R. (2005). Test fever: What the gaokao means to Today's students, teachers and parents. China Today, 54(9), 34-36;

QIAN, M. H. (1998). Students: To be honest. Beijing: HR press.

REN, S. L. (2011). High school students in 1980s. Beijing: New Star Press.

SHU, X. C. (1960). (Ed.) Literature of modern education development. Beijing: People Educational Press.

SUN, M. X. (1938). Education in kindergarten. Chongqing: Xingzhi Press.

TANG, Z. H. (2002). Pupils' stories in a primary school. Shanxi Education Weekend, (271), 6.

TAO, X. Z. (1933). Collected works on Education (Vol. 2). Wuhan: Central China Normal University.

United Nations. (2009). United Nations convention on the rights of the child, committee on the rights of the child. (Fifty-first session Geneva, 25 May-12 June).

WANG, A. Y. (1981). The wall. Beijing: People’s Literature Publishing House.

WANG, S. G. (1993). Reason and insaneness. Hong Kong: Oxford University Press.

WANG, Y. (2006). Value changes in an era of social transformations: College-educated Chinese youth. Educational Studies, 32(2), 234-48.

WU, W. (2000). Research method on understanding group voices. Journal of Educational Research of Capital Normal University (in Chinese), 11(4), 87-96.

XIA, Y. (2001). Original of human right: Historical philosophy of right (in Chinese). Beijing: Press of China University of Political Science and Law.

XIONG, X. J. (2006). History of education for female. Taiyuan: Shanxi Educational Press.

XU, L. (2004 November). Farewell to Idealism: Mapping China's university students of the 1990s. Journal of Contemporary China, 13(41), 781.

XU, L. (2002). Searching for life's meaning: Changes and tensions in the worldviews of Chinese youth in the 1980s. Ann Arbor: University of Michigan Press.

YANG, D. P. (2000). Justice of education and equal opportunities. Beijing: Higher Education Press.

YIN, X. M. (2009). Analysis on the reasons that lack of students' voice (in Chinese). Journal of Educational Research Paper of Hebei Normal University, 21(3), 34-39.

Zhang, K., Li, D., \& Beck, E. J. (1999). Changing sexual attitudes and behavior in China: Implications for the spread of HIV and other sexually transmitted diseases. Aids Care, (11),581-589.

ZHANG, P. C. (2014). A juvenile under the kite: Series stories of small warrior of Red Army during 1927-1937. Guangzhou: New Century Press.

ZHANG, Y. (2003). Listen to the voices of “special” pupils. Curriculum, Teaching Material and Method, (8), 54-55.

ZHAO, Y., LIN , L., \& Hoge, J. (2007). Establishing the need for cross-cultural and global issues research. International Education Journal, 8(1), 139-150.

ZHAO, Y. L., ZHOU,X. G., \& HUANG, L. H. (2008). Chinese students' knowledge and thinking about America and China, The Social Studies, (January/February), 13-22.

ZHONG, J. W. (2005). Historical analysis and current thinking on students' right. Perspectives on Global Education, 22(11), 37-41.

ZHONG, S. H. (Ed.). (1985). A series of book walking toward to world. Changsha: yuelu Institute.

ZHOU, Z. R. (2006). Narrative: From the perspectives of the editor of tabloid newspaper of Red Guard, 40 years anniversary of memorial ceremony for culture revolution. Fort Worth TX: Fellows Press of America. 